\title{
Endoscopy assisted extended curettage in a rare case of aneurysmal bone cyst involving the $2^{\text {nd }}$ metatarsal of a child
}

\author{
Bhaskar Borgohain ${ }^{1}$, Kashif A. Ahmed ${ }^{2 *}$, Tashi G. Khonglah ${ }^{1}$
}

\begin{abstract}
${ }^{1}$ Department of Orthopaedics and Trauma, North Eastern Indira Gandhi Regional Institute of Health and Medical Sciences, Shillong, Meghalaya, India

${ }^{2}$ Department of Orthopaedics, Fakhruddin Ali Ahmed Medical College and Hospital, Barpeta, Assam, India
\end{abstract}

Received: 10 February 2020

Revised: 02 April 2020

Accepted: 06 April 2020

\section{*Correspondence:}

Dr. Kashif A. Ahmed,

E-mail: kashifbqc@yahoo.com

Copyright: () the author(s), publisher and licensee Medip Academy. This is an open-access article distributed under the terms of the Creative Commons Attribution Non-Commercial License, which permits unrestricted non-commercial use, distribution, and reproduction in any medium, provided the original work is properly cited.

\begin{abstract}
Aneurysmal bone cysts account for only $1 \%$ of all bone tumours and of these only a handful of reported cases occur in the foot. They can mimic other bone tumours on imaging studies, thus making histological diagnosis mandatory. Aneurysmal bone cyst of a metatarsal is very rare especially in children and only few cases have been reported in the literature. We report the novel management option for a rare case of an Aneurysmal bone cyst localized to the second metatarsal in a 5 years old boy who presented with limping, local pain, and minimal swelling in his left foot. Tissue diagnosis was confirmed on the basis of needle biopsy. Surgery was in the form of extended curettage using an endoscope with a high-speed burr and cautery. The remnant cavity was filled up with artificial bone graft. Histopathology analysis of the resected tissue was consistent with Aneurysmal bone cyst. There was complete healing at final follow-up at 2 years. Endoscopy assisted extended curettage appears to be an ideal treatment option as it provides a perfect visualisation of the interior of the entire cyst and use of cautery and burr more accurately under direct vision which potentially leaves only a minimal scope for recurrence. Use of artificial bone grafts instead of conventional autogenous bone grafts to reduce graft site morbidity in children and stimulate local foreign body reaction for enhancing residual tumour cell kill if any and also to promote bony sclerosis for healing.
\end{abstract}

Keywords: Aneurysmal bone cyst, Metatarsal, Curettage, Endoscopy, Artificial bone graft, Benign bone tumour

\section{INTRODUCTION}

Aneurysmal bone cyst (ABC) is a rare cystic, vascular and expansile bone lesion that remains a challenge in terms of accurate diagnosis and curative treatment even today. They represent $1 \%$ of all bone tumours. ABCs were first described by Jaffe and Lichenstein in 1942 when they described pelvic and spine lesions that "when exposing the lesion and opening into its thin wall, the surgeon was immediately confronted by a large hole containing much fluid blood". ${ }^{1}$ These benign expansile lesions produce cavities within the bone that fill with blood and are lined by proliferative fibroblasts, giant-cells, and trabecular bone. $^{2}$ The pathogenesis of ABC remains unclear with theories ranging from a post-traumatic, reactive vascular malformation to genetically predisposed bone tumours. ${ }^{3,4}$ The most widely accepted pathogenesis is that ABC's involve a local circulatory disturbance leading to markedly increased venous pressure and the development of a dilated and enlarged vascular bed within the affected bone area. ${ }^{5}$ However, the recent identification of recurrent chromosome abnormalities has challenged this historical perception. ${ }^{6}$

ABCs are commonly seen during childhood and young adulthood with a median age of 13 years, and $90 \%$ of lesions are found prior to age $30 .^{5}$ Females are slightly more affected with an estimated M:F sex ratio of $1: 1.16 .^{5}$ 
ABCs have a predilection for the metaphysis of long bones including the femur, tibia/fibula, and upper extremity. However, ABCs can present in the spine, pelvis, sacrum, clavicle, foot, and fingers, rendering this a disease that can afflict the entire skeleton. They occur rarely in the bones of the metacarpals and metatarsals, which are mainly published as case reports in journals. The early radiographic appearance of the $\mathrm{ABC}$ in the long bones is a subperiosteal, metaphyseal eccentric lesion, elevating and inflating the periosteum and progressively eroding the cortex. ${ }^{7}$ The osteolytic area often contains septa and ridges, producing a honeycomb pattern. Sometimes the lesion shows calcification in the central area. ${ }^{8}$ The imaging studies, even CT scan and MRI sometimes do not provide clear diagnostic criteria for the diagnosis of $\mathrm{ABC}$ and $\mathrm{ABC}$ is sometimes added on to a list of diagnosis including eosinophilic granuloma, giant cell tumour, unicameral bone cyst. It is also technically difficult to evaluate small terminal areas like foot and hand by MRI. Imaging diagnosis remains a diagnosis of probability and should always be confirmed by a biopsy. ${ }^{9}$ Needle biopsies are sometimes a problem because the material obtained may consist of mostly blood elements. Often, an open biopsy is necessary to establish the diagnosis.

The standard of care for ABCs is curettage with or without bone-graft depending on the resultant void. Despite best efforts at curettage, clinical series have shown highly variable recurrence rates, with some series showing rates as high as $59 \% .{ }^{9}$ As a result, various adjuvants have evolved to reduce recurrence including the use of cement, high-speed burr, argon beam, phenol, and cryotherapy. Currently, there exist no high-level controlled, comparative studies regarding adjuvant efficacy, and the specific adjuvant strategy utilized is largely institution dependent. As such, the literature on adjuvant efficacy consists largely of case-series from single institutions. We are sharing our experience for a rare $\mathrm{ABC}$ lesion diagnosed in a metatarsal of a child and its management.

\section{CASE REPORT}

A five years old boy presented with pain and local swelling in second metatarsal of his left foot in the past 6 months. Initially it was neglected by the parents but once the child started limping, he was brought immediately to hospital. Physical examination showed that the swelling was firm, tender and immobile. Active range of movement of toes was painfully restricted compared to the normal side. There was no history of trauma or associated fever. The past history did not reveal anything significant. Radiologically, X-ray showed a lesion with widening of medullary canal and thin cortical wall in the second metatarsal of the foot with multiple septae within the lesion (Figure 1).

MRI suggested it to be an expansile thin walled cystic lesion which was filled with fluid and multiple septae (Figure 2).

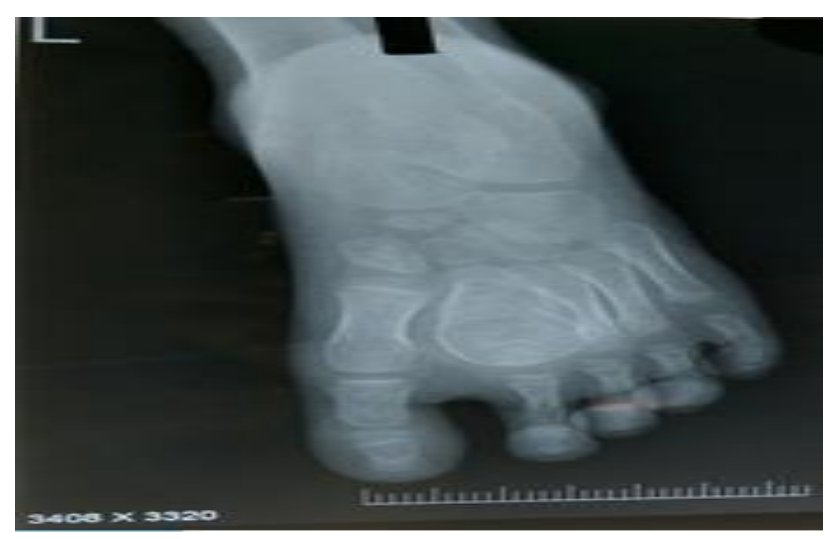

Figure 1: Lesion in the $2^{\text {nd }}$ metatarsal with multiple septae within it.

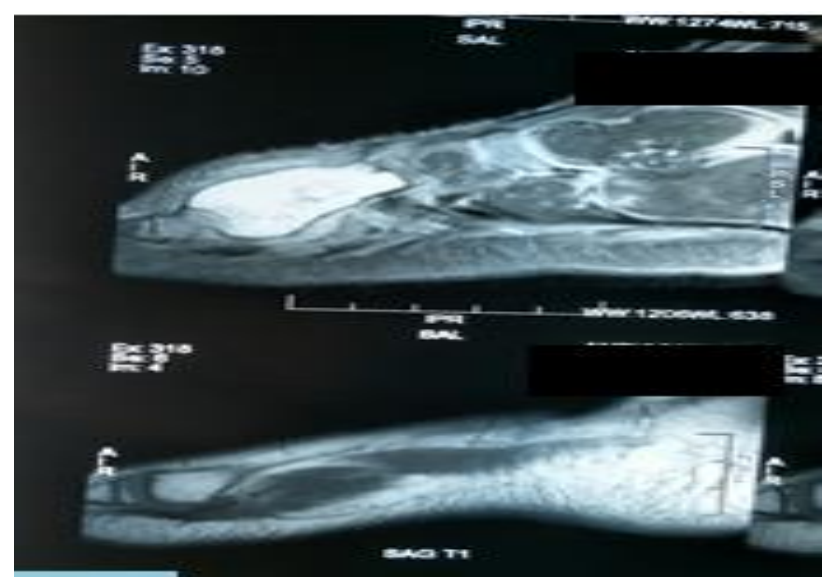

Figure 2: MRI showing expansile cyst with multiple septae.

There was sparing of the articular surface but surrounded by subcutaneous oedema. Needle biopsy suggested it to be an aneurysmal bone cyst.

Surgery involved extended curettage of the lesion through a dorsal longitudinal incision over the second metatarsal. Endoscope was used to provide an excellent direct visualisation of the entire cystic cavity (Figure 3).

Completion of the curettage was done using a high-speed burr and a cautery (Figure 4).

The remnant cavity was filled with artificial bone graft (modified hydroxyapatite blocks) (Figure 5).

The foot was immobilised in a short leg slab for 3 weeks, after which patient received active assisted physiotherapy exercises of the foot. Histopathology was consistent with aneurysmal bone cyst, which showed blood clots separated by fibrous septa and occasional solid fragments of tissues containing loose spindly stroma to cellular stroma with interspersed osteoclastic like giant cells along with hemosiderin laden macrophages and inflammatory infiltrate. Typically, osteoid formation was observed. 
Regular follow-up was done for 2 years and the child had satisfactory functional and cosmetic results (Figure 6).

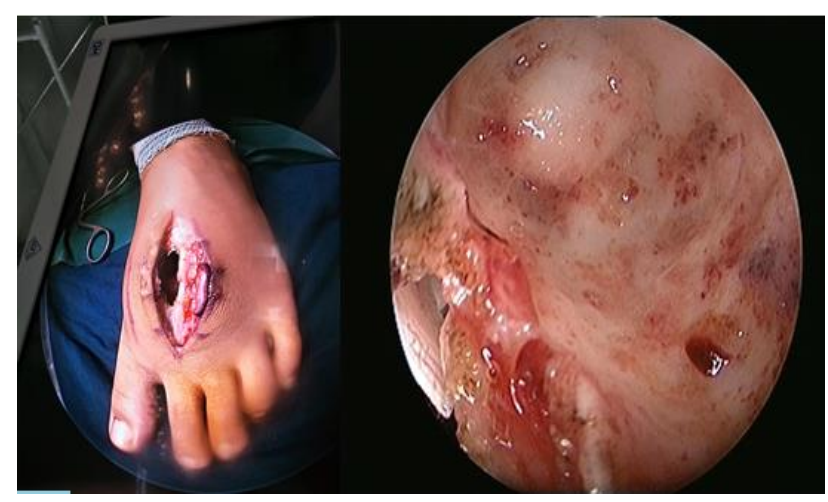

Figure 3: Endoscopic view of the cyst.

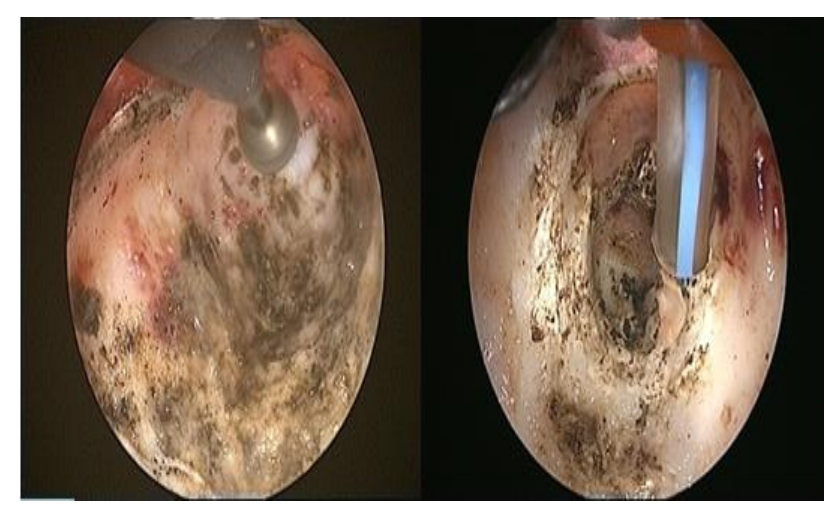

Figure 4: Use of burr and cautery.

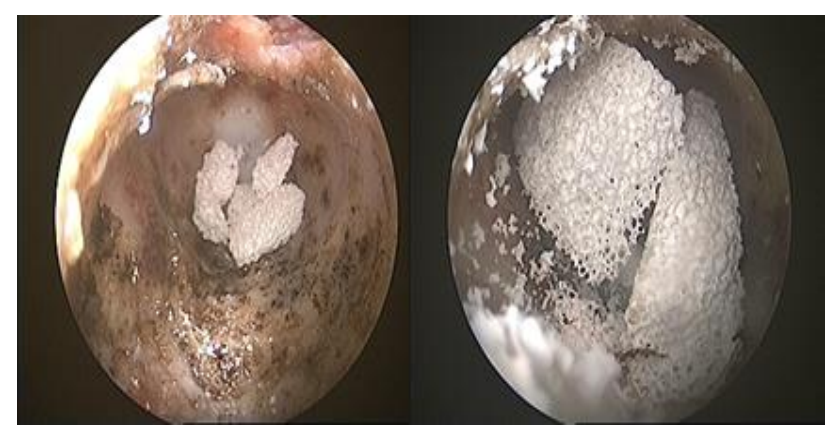

Figure 5: Artificial bone graft in cavity.

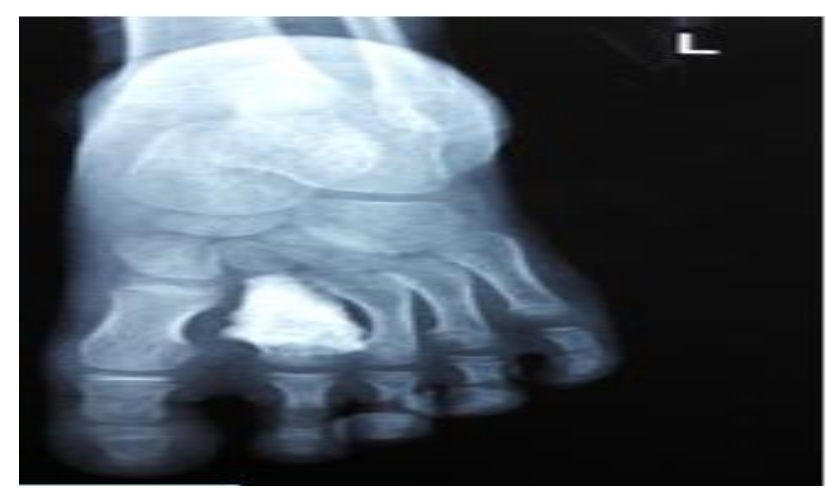

Figure 6: X-ray at 2 years follow up.
Radiographic examination (X-ray and CT scan) demonstrated osseous integration with the artificial bone graft with no signs of recurrence or residual lesion (Figure 7).

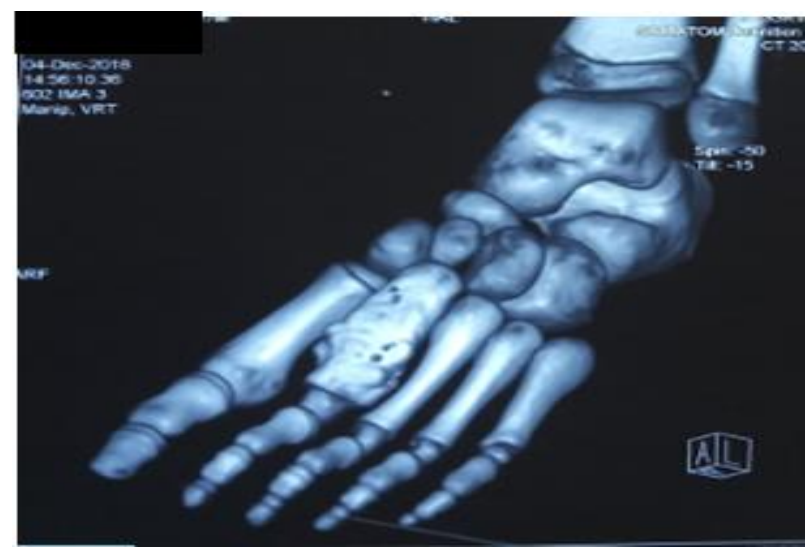

Figure 7: CT scan at 2 years follow up.

\section{DISCUSSION}

The standard of care for ABCs is curettage with or without bone graft depending on the resultant void. Despite best efforts at curettage, clinical series have shown highly variable recurrence rates, with some series showing rates as high as $59 \% .{ }^{10}$ As a result, various adjuvants have evolved to reduce recurrence including the use of cement, high-speed burr, argon beam, phenol, and cryotherapy. Adjuvant therapy is intended to treat microscopic disease contamination within the tumour bed to lower the incidence of local recurrence.

Currently, there exist no high-level controlled, comparative studies regarding adjuvant efficacy, and the specific adjuvant strategy utilized is largely institution dependent. As such, the literature on adjuvant efficacy consists largely of case series from single institutions. Basarir et al reported that two of three cases that were initially treated with curettage and grafting, recurred. ${ }^{11}$ Similarly, in a case series by Frassica et al, curettage and bone grafting in seven cases was associated with four recurrences. $^{12}$

Compared with the long bone of the extremities, the bones of the foot are small. Under the magnifying view of arthroscopy, there are fewer blind spots in the operative field and a thorough curettage could potentially be performed. ${ }^{13}$ Endoscopy provides the advantage of accurately assessing thoroughness of tumour resection via direct examination of the cavity for complete removal of the cyst. In some cases, cryosurgery and sclerotherapy were used as an adjuvant intralesional treatment for aneurysmal bone cyst arising in the hand and foot. ${ }^{14}$ Example of such procedure can be percutaneous guided injections of polidocanol, sterioid, calcitonis etc. Though percutaneous (minimally invasive) injection of sclerosing agent like polidocanol is becoming popular, but there are 
reports in literature that it can lead to ARDS. These treatments are difficult to use in the small bones of the hand as well as foot and may damage surrounding intact tissue and cause serious complications such as neuropraxia, postoperative fracture, burn and infection. Low- dose irradiation has also been reported to be an effective method of treatment however it is not used routinely because of potential for malignant transformation and wound necrosis, which may happen more easily in distal lesions. Although a $3.7 \%$ local recurrence rate was reported with cryosurgery, there is a potential risk of amputation of small bones/digits.

Various studies have given options of filling the cavity/void, which include autografts, allografts and bone cement etc. The advantages of autograft include improved rate of graft incorporation and lack of immunogenic concerns; however, it may need a longer operating time and can result in donor site morbidity. Use of allograft is an alternative option. However, fracture and nonunion are its common complications besides a risk of disease transmission. However, with safety precautions, including donor selection and biological investigations, such risks are low. In a study by Mankin et al, 110 patients underwent bone grafting and 20 cementations. ${ }^{15}$ The rates of local recurrence were $21.8 \%$ and $25 \%$, respectively. No statistically significant differences were noted between the groups $(\mathrm{p}>0.05)$.

In our case, endoscopy assisted extended curettage appears to be an ideal treatment option as it provides a perfect visualisation of the interior of the entire cyst and use of cautery and burr more accurately under direct vision which potentially leaves only a minimal scope for recurrence. We have used artificial bone graft to prevent graft site morbidity considering the age of the patient. We hypothesize that artificial bone graft has an additional advantage of stimulating a locally controlled foreign body reaction which can potentiate a healing response by enhanced osteosclerosis and residual tumour cell kill that needs however to be proved in future studies.

\section{CONCLUSION}

Aneurysmal bone cysts are aggressive benign lesions with high rates of recurrence rendering its treatment uniquely challenging. We emphasize that histological examination is essential for a precise diagnosis. The standard of treatment remains curettage and grafting to fill the bone void, but the adjuvant or alternative treatment methods to reduce recurrence are numerous.

Our case report describes a very rare lesion: an aneurysmal bone cyst of the metatarsal and confirmed by both radiological and histological examinations for the accuracy of diagnosis. It documents the role of endoscopy and adjuvant therapy (high speed burr, cautery) as well as cavity filling using artificial bone graft. In summary, given the lack of high-level comparative trials in the use of adjuvants or alternative methods, treatment decisions are largely based on personal experience and institutional preference, but such decision should be based on potentially improving outcomes.

\section{Funding: No funding sources \\ Conflict of interest: None declared \\ Ethical approval: Not required}

\section{REFERENCES}

1. Jaffe HL, Lichtenstein L. Solitary unicameral bone cyst: with emphasis on the roentgen picture, the pathologic appearance and the pathogenesis. Arch Surg. 1942;44(6):1004-25.

2. Fletcher CDM, Unni KK, Mertens F. Pathology and genetics of tumours of soft tissue and bone. In: World Health Organization classification of tumours. Lyon: IARC Press; 2002.

3. RatcliVe PJ, Grimer J. Aneurysmal bone cyst arising after tibial fracture. J Bone Joint Surg (Am). 1993;75:1225-27.

4. Leithner A, Machacek F, Haas OA, Lang S, Ritschl P, Radl R, et al. Aneurysmal bone cyst: a hereditary disease. J Pediatr Orthop B. 2003;13:214-7.

5. Campanacci M, Bertoni F, Bacchini P. Aneurysmal bone cyst. In: Campanacci M, Bertoni F, Bacchini P, eds. Bone and soft tissue tumors. Vienna: Springer; 1990; 725-751.

6. Althof PA, Ohmori K, Zhou M, Bailey JM, Bridge RS, Nelson M, et al. Cytogenetic and molecular cytogenetic windings in 43 aneurysmal bone cysts: aberrations of $17 \mathrm{p}$ mapped to $17 \mathrm{p} 13.2$ by Xuorescence in situ hybridization. Mod Pathol. 2004; 17:518-25.

7. Cottalorda J, Gouin F. Kysteosseuxanevrismal (Aneurysmal bone cyst). In: Chotel F, Gouin F (eds) Tumeurs osseuses benignes (Benign osseous tumors). Paris: Elsevier; 2005: 188-200.

8. Mankin HJ, Hornicek FJ, Cruz OE, Villafuerte J, Gebhardt MC. Aneurysmal bone cyst: a review of 150patients. J Clin Oncol. 2005;23:6756-62.

9. Cottalorda J, Bollini G, Panuel M, Scheiner C, Jouve JL, Labriet C, et al. Le kysteanevrismal des oschez l'enfant (Aneurysmal bone cysts in childhood). Rev Chir Orthop. 1993;79:272-80.

10. Caprio DMR, Murphy MJ, Camp RL. Aneurysmal bone cyst of the spine with familial incidence. Spine. 2000;25:1589-92.

11. Leithner A, Long S, Windhager R, Karlic H, Koyz R, Haas OA. Expression of insulin like growth factor (IGF-1) in ABC. Mod Pathol. 2001;14:1100-4.

12. Leithner A, Windhager $R$, Lang $S$, Haas OA, Kainberger F, Kotz R. Aneurysmal bone cyst. A population based epidemiologic study and literature review. Clin Orthop Relat Res. 1999;363:176-9.

13. Toepfer A, Lenze U, Gerdesmeyer L, Pohlig F, Harrasser N. Endoscopic resection and allografting for benign osteolytic lesions of the calcaneus. Springer Plus. 2016;5:427. 
14. Mendenhall WM, Zlotecki RA, Gibbs CP, Reith JD, Scarborough MT, Mendenhall NP. Aneurysmal bone cyst. Am J Clin Oncol. 2006;29(3):311-5.

15. Mankin HJ, Hornicek FJ, Cruz OE. Aneurysmal bone cyst: a review of 150 patients. J Clin Onocol. 2005;23:6756-62.
Cite this article as: Borgohain B, Ahmed KA, Khonglah TG. Endoscopy assisted extended curettage in a rare case of aneurysmal bone cyst involving the $2^{\text {nd }}$ metatarsal of a child. Int J Res Orthop 2020;6:638-42. 